\title{
A Didactical Analysis of Teaching Practices Around Differentials Equations in Tunisian School Context
}

\author{
Sonia Ben Nejma ${ }^{1, *}$, Anis Jabrane ${ }^{2}$ \\ ${ }^{1}$ Department of Mathematics, University of Carthage, LARINA, Tunisia \\ ${ }^{2}$ Department of Didactic, Virtual University Tunis, Tunis, Tunisia \\ Email address: \\ sonianejma@yahoo.com (S. B. Nejma), anis1.jabrane@gmail.com (A. Jabrane) \\ ${ }^{*}$ Corresponding author
}

\section{To cite this article:}

Sonia Ben Nejma, Anis Jabrane. A Didactical Analysis of Teaching Practices Around Differentials Equations in Tunisian School Context. Science Journal of Education. Vol. 9, No. 5, 2021, pp. 157-169. doi: 10.11648/j.sjedu.20210905.13

Received: September 1, 2021; Accepted: September 22, 2021; Published: October 12, 2021

\begin{abstract}
The teaching of differential equations is often viewed from an interdisciplinary perspective that justifies the rationale for this notion in the secondary cycle. The history of the teaching of this notion in the Tunisian educational system shows a diversity of approaches which seem to evolve in the direction of modeling extra-mathematical situations and dialectic between semiotics registers. This research is part of the anthropological theory of didactics and analyzes the didactic transposition process developed by the Tunisian institution around differential equations over successive reforms. Three dimensions of analysis were taken into account in this study: a historical-epistemological dimension which makes it possible to identify the dynamic nature of the notion of differential equation through the stages of its constitution and to determine its meaning through the problems addressed in teaching and their development, an institutional dimension addressed by ecology and praxeology analyses based on the programs and official textbooks. Current institutional practices allow us to glimpse a dynamic at scale relating to the teaching of this notion. This aspect is nourished by sets of frameworks, flexibility between registers and interdisciplinary praxeology mobilized upstream and downstream of the work of algebraic resolution. Professional entry allows us to question the constraints for their effective implementation in classes. This dimension is analyzed from ten student notebooks considered as a first revealer of teaching practices in terms of resistance or change. This analysis of the notebooks make it possible to discover the main characteristics of the institutional relationship. The result of the analysis shows that the personal relationship of teachers perceived through the analysis of their didactic preparation with the object of knowledge differential equations, is not suitable to institutional relationship with this same object of knowledge.
\end{abstract}

Keywords: Differential Equation, Mathematical and Didactical Praxeology, Institutional Practices, Teaching Practices

\section{Introduction}

The teaching of differential equations (DE) has undergone significant changes over the course of the reforms of the Tunisian institutional system, including a focus on the modeling of extra-mathematical situations and a strengthening of the problem-solving approach. The official frames of reference seem to suggest new forms of practice in favour of an interdisciplinary approach and a reinforced dialectic between the registers of semiotic representations. These characteristics affect both algebraic equations that were the subject of our previous work in the same institutional context [5-7] as that of DE, the subject of a work carried out in a research master's degree in didactics mathematics [20]. It seemed interesting to us to observe once again the upheavals induced by the current Tunisian reform on the practices of experienced teachers, for another study theme, after ten years of adapting practices to curricular changes.

1) Do the changes brought about since 2004 by the current Tunisian reform induce changes in teaching practices?

2) Do you see any resistance? 
3) What choices do they adopt after several years of adapting to the reform?

4) What are the explanatory reasons for these changes with regard to institutional injunctions?

To provide answers to the above questions, we situate this work within the framework of the anthropological theory of didactics through the study of mathematical organizations of teaching knowledge that can be identified in practice [14]. Two dimensions of analysis practices are therefore considered in our work: an institutional dimension to analyze the process of didactic transposition of the object of knowledge of differential equations. Mathematical organizations are referred to as institutional praxeological organizations. This institutional reference is a crucial axis of our work [5, 7-8], since it involves the impact of studying of a reform on teaching practices in the short and long term which concerns the professional dimension, it is a question of being interested in the practices of the teachers, more precisely, the potential specificities of the study of the professional practices of teachers in the context of a reform [2]. Whatever their foundations are, the changes were brought about by a reform's work habits and balances in the relationship. Prescribing new practices and new objectives, thus inevitably represents a source of change or resistance to change for teachers who are caught up in logic of management. Taking this dimension of analysis into account raises questions related to forms of teaching practices $[5,17]$ which may be due to the order of resistance to change or linked disruption of routine practices.

"Is resistance to change also present: an active force when we want to preserve something or an organization that is stable and thrifty, a force of inertia when we oppose change in an active way or in a passive way" [2] (p. 324).

Whether it is about resistance, regulations, or not, they are made aware of the teachers involved, these forms of practice can be considered as an echo of endogenous disturbances in the system.

"Regulations or attempts at regulations respond to disturbances that can be said to be endogenous, in the sense that they are triggered consciously or not by the actions of the teacher or the students. Disturbances can be exogenous, for example, of ministerial authority" [15] (p. 246).

First, we present the theoretical tools that equipped our research. Then we present the main results delivered by the institutional study and that of teaching practices by illustrating these analyses with extracts from the official Tunisian scientific terminal manual and student notebooks.

\section{Background and Literature Review}

\subsection{Didactic Transposition}

The concept of didactic transposition [12] on which this study is based refers to all the transformations that knowledge undergoes in order to be taught. The study of this process makes it possible to question the legitimization of educational content perceived in the eyes of the actors of the institution as reference knowledge. In this context, it is possible to question the differences between the knowledge of reference and the knowledge taught by the constraints that the educational institution imposes. In this approach, reference knowledge undergoes transformation mechanisms into knowledge to be taught and we speak of external transposition. This is under the control of what Chevallard calls the noosphere:

"It is the noosphere, ... which will proceed to the selection of the elements of scholarly knowledge which is designated as " knowledge to be taught", will then be subjected to the work of transposition; The noosphere, itself, again, will assume visible part of this work, what we can call the external work of didactic transposition, as opposed to the internal work, which continues inside the system of teaching, long after the official introduction of new elements in the knowledge taught" [12] (p. 31).

In turn, this knowledge is conducted in teaching to know how to teach, which refers to internal didactic transposition. This depends on the teacher's margin of interpretation and creation and then on the actual knowledge offered to the students and to the knowledge to be taught.

On the other hand, when a teacher prepares for a lesson, the knowledge text is, at that precise moment, temporarily stable. However, this text still offers the teacher a variety of choices. The choices made by the teacher to construct his or her course modify the knowledge to be taught as well as the effective realization of the course project in front of students will inevitably lead to changes in this project. This work of the teacher is therefore a transpositive work.

"The second major type of task at the heart of the teacher's activity obviously consists in directing the study of a determined mathematical organization that is to say to lead their construction or transposition in the classroom of this organization" [13] (p. 45).

Thus, the role of the teacher is central in the process of internal didactic transposition: he or she is responsible for" preparing" the knowledge to be taught for the knowledge taught. Thus, according to [22] "prepared" knowledge designates the result of didactic and mathematical choices made by a teacher to teach an object of mathematical knowledge. This "prepared" knowledge "Figure 1" is identified with the course project and thus constitutes an intermediate stage in the process of internal didactic transposition which passes from knowledge to be taught to knowledge taught.

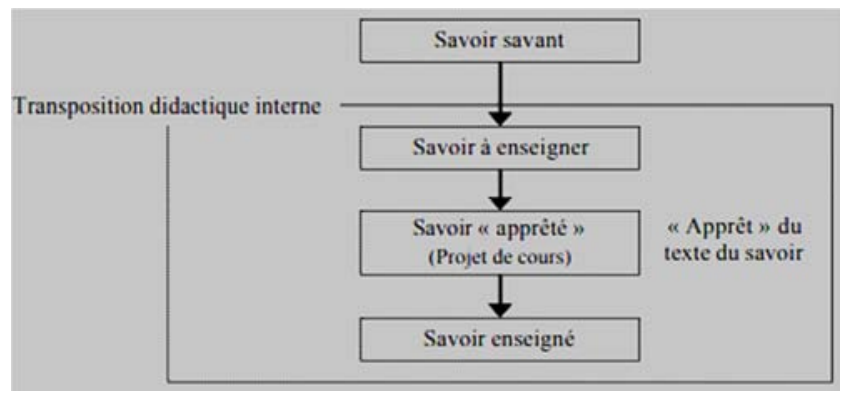

Figure 1. Knowledge prepared'in the process of internal didactic. 
For this study, we have considered two dimensions of analysis of practices: an ecological dimension which allows us to question the conditions of the viability of this notion and its evolution over the successive reforms of Tunisian education and a praxeological dimension, allowing to model institutional practices and those prepared by mathematics teachers in final year.

\subsection{The Concepts of Niches and Habitat}

A fundamental point of the ecological approach is to consider that an object of knowledge cannot live in isolation. It is always interrelated with other objects of knowledge. In this perspective, [23] (p. 35) develops the idea of the law of "All structured". The viability of a knowledge object depends on other objects, without them, there is no reason to exist. The ecological analysis of an object of knowledge is organized around two concepts: the habitat which designates the places of life of the object and the conceptual environment of this object of knowledge and the niche which designates the function of this object in the system of objects with which it interacts.

"Regarding mathematical objects, these are similar objects that a given mathematical object needs to live in a considered ecosystem" [1] (p. 112).

It is particularly these theoretical tools of the ecological approach to which we have referred to in our analysis of the "text of knowledge". This makes it possible to identify the links between the differential equations and other mathematical concepts in play (such as primitives, the derivative of functions) and characterize their evolution and the functions assigned to them within the field of study, as it is mentioned:

"..The ecological analysis of the teaching text...allows the exploration of the institutional closure of the universe of teaching knowledge, and consists of the analysis of the interrelationships between objects, sub-objects and overobjects present in the teaching text, in order to highlight, in particular their habitats and ecological niches, trophic levels, etc. It is then at this level that the problem of identifying institutional objects and analyzing the content of institutional and official relationships to an $\mathrm{O}$ object and their evolution can be posed" [1] (p. 233).

The articulation of two notions of habitat and niche makes it possible to examine in a way the "address" of the differential equations object by articulating it with the didactic levels of codetermination. These levels are ranked as follows, going from the most specific to the most general: subject, theme, sector, field, discipline, pedagogy, school, society. Thus, according to [15], each level imposes determined constraints on the deeper levels, while these levels in return exert pressure on the higher levels which tends to modify the constraints having their place there.

\subsection{The Concept of Praxeology}

The anthropological theory of didactics [11] considers that in the last instance, any mathematical and human activity can be modeled in praxeology denoted $[\mathrm{T} / \tau / \theta / \Theta]$ which consists in accomplishing a task of a certain type $\mathrm{T}$, by means of a technique $\tau$, justified by a technology $\theta$ allowing to think it, even to produce it, and justifiable in turn by a theory $\Theta$. [T/ $\tau]$ being the practice or again the know-how and $[\theta / \Theta]$ the logos or even the knowledge. For example, if the task is to solve a second order differential equation, one could decide to use a preprogrammed function in Mathematica to do it, or to proceed algebraically by finding a homogeneous solution and a particular solution, which would be techniques. Similarly, the logos can be on different levels; [11] considers technologies (the justifications for the methods chosen) and theories (the foundations of technology) as distinct levels of discourse. The use of an algebraic technique to solve DE can be justified by the algorithm of solving homogeneous equations and the method of the variation of the constant for the particular solution. A computer technique can be justified by its speed and precision in comparison to a manual technique. But the choice of one technique over another also depends on the characteristics of the activity and is also based on the mathematical or computer knowledge that the students have in their possession.

Moreover, a description of the knowledge of reference can be carried out by means of a historic-epistemological analysis making it possible to make the link between the construction of this mathematical notion and the history of its teaching. In the following part we briefly present the results obtained of our historical-epistemological analysis around the notion of DE.

\section{Differential Equations in Knowledge: Epistemological Findings}

According [25] the first appearance of DE dates back to the year 1638 when Florimond Debeaune (1601-1652) proposed two geometrical problems on the construction of the curves starting from the properties of the tangent: It is a question of building in a geometrical context of the curves starting from the properties of the tangent:

"Find a curve $\mathrm{y}(\mathrm{x})$ for which at each point $\mathrm{P}$, the segment delimited by the points of intersection with the axis of the $\mathrm{x}$ of the tangent (PT) and of the perpendicular (PN) has this same axis is constant".
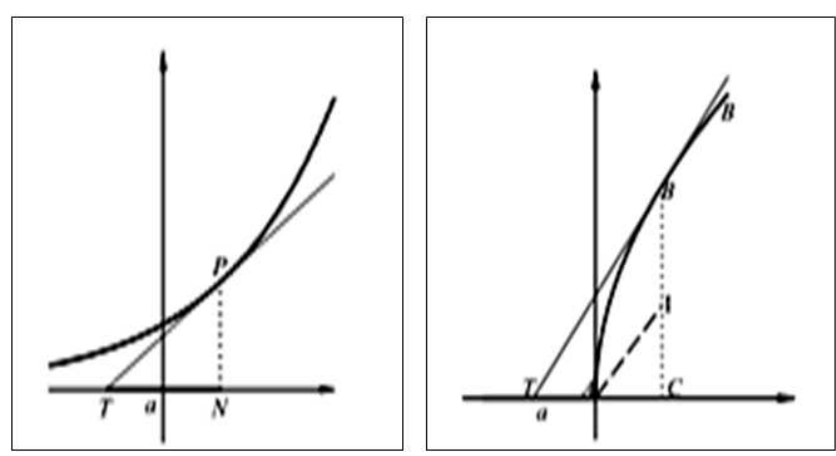

Figure 2. First problem and second problem. 
In the early days, DE were associated with solving problems in the framework of physical and geometric quantities, but they soon became an effective tool for analyzing natural phenomena. The historical genesis of this notion can be split into three great eras: The first refers to the algebraic aspect or the exact resolution by explicit formulas, finite expressions, developable in whole series, integral expression... These first attempts of the inventors followed the appearance of new methods of resolution for lack of solving certain types of equations. The second period refers to the numerical aspect. The work of Euler (1707-1783), includes the development of numerical methods which provide approximate solutions for most DE. New numerical methods were then developed by C. Runge (1856-1927). The third period, which dates from the second half of the 19th century, refers to the qualitative aspect emerging with the work of Poincaré (1854-1912) which opens a new avenue for the resolution of nonlinear DE.

The historical-epistemological analysis conducted as part of this research makes it possible to highlight important findings for a characterization of the reference knowledge around the equations. First, the importance of the context of the emergence of this notion, which has developed in a variety of frameworks [10], notably the framework of quantities (geometric and physical) then the algebraic and numerical framework. Artigue identified in his work three main frameworks related to the teaching of this notion: the algebraic framework, the numerical framework and the geometric framework that she defines it as follows:

"The algebraic framework will be for us that of the" exact "resolution by explicit formulas, finite expressions, development in series, integral expressions; the digital frame will be that of the approximate digital resolution; finally, the geometric framework will be that of the qualitative study of the flow of the equation" $[3,4]$ (p. 183).

The second interesting observation for our study is that of the variety of representations of DE that have emerged simultaneously with the evolution of solving techniques. This refers to the notion of semiotic representation register developed by [19]. In the classical teaching of DE, the links between the algebraic and graphical registers are almost absent at the level of institutional practices developed or envisaged with the sole aim of reinforcing the pupils' achievements around the graphical representations of usual functions solutions, downstream of algebraic resolution. However, a graphical approach to DE is not so easy to install in secondary education for several reasons.[3, 4] evokes several constraints to the implementation of this approach, epistemological constraints in relation to fine reasoning of the analysis that the final year students could not resolve, cognitive constraints which refer to new notions other than 'algebraic approach which is part of a certain continuity in the teaching of analysis and didactic constraints in relation to what the author qualifies as algorithmic reduction, the inframathematical status of the graphic framework and the myth of resolution complete this leads us to a third finding related to graphic work, more particularly to the qualitative study of solutions. This study has historically contributed to the emergence of new techniques making it possible to go beyond the algebraic aspect which does not allow in all cases to however, this approach is by no means considered in terminal in the Tunisian context but certain activities proposed in the only official textbook of $4^{\text {th }}$ year of secondary education for the mathematics section have led us explore the functioning of the graph in the developed praxeologies. With reference to the work of [21] three operating modes of the graph can be identified at the level of institutional practices, the nomographic mode which corresponds to the use of the graph as an abacus and calculation tool. The graph is then an effective algorithmized means making it possible to obtain numerical results (in general approximated) by local procedures, the ideogrammatic mode which corresponds to the use of the graph as an ideogram, that is to say as a graphic sign referring to an idea and the operating mode which corresponds to a use of the graphic as an interactive process, not algorithmized: the task cannot be carried out without the graphic, but the answer is not given directly by the graphic, it must be constructed by the subject interacting with the graph, without having a standardized algorithm. [9] (p. 221) reveals that the graph is often used in an ideogrammatic mode and that its processing is essentially ad hoc, which represents an obstacle for a global functioning of the graphical representatives.

These historical and epistemological characteristics of the object of knowledge DE equipped by didactic approaches make it possible to better understand what is really done at the level of the knowledge to be taught in the institution concerned and to interpret the changes identified with regard to the historical genesis of this notion.

\section{Research Methodology and Context}

\subsection{Methodology}

The theoretical framework of anthropological theory of didactics (TAD) allows us to study what we have called exogenous disturbances $[5,7]$ (i.e. relating to the institutional context). We analyze the changes prescribed by the considered institution in the mathematical and didactic organizations of the knowledge to be taught. We are not content with the current reform of the current programs. Taking into account the different periods of teaching seems crucial to analyze the practices of teachers from the point of view of the influences of institutional practices encountered by a subject throughout the history of the institutions to which he has been subjected and considered by Chevallard: a person is almost a bad subject of the institution to a certain extent because his relationship to knowledge is formed by the integration over time of the influences exerted by the various institutional relationships to which it has been subjected. Some research based on this framework [5, 16-17] reveals contrasting teaching practices (of a given study topic) which, although contemporary, refers to 
periods of previous teaching. This is precisely what we explore further in this work by highlighting the impact of institutional changes, after a phase of adaptation to a reform on teaching practices.

\subsection{The Institutional Context}

Our study takes place in the Tunisian context and we are particularly interested in the last year of high school, in particular the science terminal class. Let us specify a few elements of the institutional context that seem important to us. In Tunisia, there is a unique official book for each level of education made available to students and teachers. The uniqueness of the official manual in this context seems to us to play a decisive role from the point of view of the teacher's room for maneuvering in the choice of praxeologies to be developed in class. On the other hand, the chapter on DE is the last chapter of the manual and includes the same content for the "mathematics" and "experimental sciences" sections. The single textualization of the knowledge to be taught seems a priori likely to constrain the practices of teachers more than in other contexts where the diversity of textbooks could favor the existence of several alternatives.

The official programs relating to DE have undergone significant curricular changes in the course of successive reforms of Tunisian education. The table 1 below summarizes the main teaching periods identified and revealing changes in official programs:

Table 1. The different Tunisian curriculum reforms.

\begin{tabular}{lllll}
\hline Classic Period & Modern Math Period & Counter-Reformation Period & Contemporary Period & Current Period \\
\hline $1958-1968$ & $1968-1978$ & $1978-1991$ & $1991-2002$ & From 2004 \\
\hline
\end{tabular}

\subsection{Criteria for Analyzing Praxeologies Developed Around Differential Equations}

The first entry in this analysis is to highlight the DE niches and habitats for each reform. The identification of these ecological aspects seems to suggest a priori identification of the didactic levels of codetermination and the one-off $\mathrm{OM}$ most developed in the manual. In addition, we consider in this work the following analysis criteria allowing us to study the praxeology developed around the DE in the Tunisian scientific terminal textbook.

1) The degree of formalism attached to the concept.

2) The validation modes which refer to the technologicaltheoretical block accompanying implicitly or explicitly the techniques mentioned or called upon by the authors of the manual.

3) The context invoked by the proposed situations and its frequency of occurrence.

4) The degree of clarification of the techniques: implicit or explicit.

5) The status of the tool or object [18] of the concept of $\mathrm{DE}$ in the proposed situations.

6) The semiotic registers are most called upon by these mobilized activities.

7) The most popular types of conversion between registers.

\section{Differential Equations in Teaching Knowledge}

\subsection{New Institutional Orientations}

In 2004, new programs came into effect and new requirements for the teaching of mathematics were recommended, an epistemological reflection on the contents of the programs seemed to be required in view of an algorithmisation of techniques and a focus on computational and formal aspects, to the detriment of the development of a spirit of analysis and synthesis, in a problem-solving context:

"At a time when the volume of knowledge doubles every fifteen years and where the sources of knowledge multiply and become more and more accessible, thus removing the school's monopoly in the matter; it would be wrong, even dangerous, to continue to inculcate in students masses of knowledge, in a considerable number of disciplines, at a rate which favors memorization and the quasi-mechanical application of rules and algorithms rather than putting them into action problem analysis, synthesis and resolution processes" [34](p. 9). In addition, we note significant changes in the areas of study that evolve from trigonometry to functions through equations and then through the integration of functions. The table below summarizes the main characteristics identified in this work.

Table 2. Changes in the levels of didactic codeterminations relating to DE over the course of the Tunisian reforms

\begin{tabular}{|c|c|c|c|}
\hline & & Fields of study & Study subjects \\
\hline \multirow{2}{*}{ Classic period } & Program1959 & Algebra-Analysis concepts-Trigonometry & Trigonometry \\
\hline & Program 1965 & Algebra & Equations and inequalities \\
\hline \multirow{2}{*}{ Modern Maths period } & Program 1968 & Arithmetic-algebra and notions of analysis & Analysis \\
\hline & Program 1970 & Algebra et analysis & Integration of usual functions \\
\hline \multicolumn{2}{|c|}{ Period Counter-reform } & Analysis & Integration of usual functions \\
\hline \multicolumn{2}{|c|}{ Period Contemporary Program1997 } & Analysis & Integration of usual functions \\
\hline
\end{tabular}




\begin{tabular}{|c|c|c|}
\hline & Study themes & Study subjects \\
\hline Program1959 & ED & $\begin{array}{l}y^{\prime}=f(x), y^{\prime}=f(y) \\
y^{\prime}+a y+b=0 \\
y^{\prime \prime}=P(x)\end{array}$ \\
\hline Program1965 & ED & $\begin{array}{l}y^{\prime}=f(x), y^{\prime}=f(y) \\
y^{\prime}+a y+b=0 \\
y^{\prime \prime}+w^{2} y=0\end{array}$ \\
\hline Program1968 & ED & $\begin{array}{l}y^{\prime}=f(x), y^{\prime}=f(y) \\
y^{\prime}+a y+b=0 \\
y^{\prime \prime}+w^{2} y=0\end{array}$ \\
\hline Program1970 & ED & $\begin{array}{l}y^{\prime}=P(x), y^{\prime \prime}=P(x) \\
y^{\prime}=a y, y^{\prime \prime}+w^{2} y=0\end{array}$ \\
\hline Program1980 & $1^{\text {st }}$ and $2^{\text {nd }}$ orderED & $\begin{array}{l}y^{\prime}=P(x), y^{\prime \prime}=P(x) \\
y^{\prime \prime}+w^{2} y=0 \\
y^{\prime}-a v=0\end{array}$ \\
\hline Program 1997 & $1^{\text {st }}$ and $2^{\text {nd }}$ orderED & $\begin{array}{l}y^{\prime}-a y=f \\
y^{\prime \prime}+a y^{\prime}+b y=0 \\
y^{\prime \prime}+w^{2} y=0\end{array}$ \\
\hline Program 2004 & ED & $\begin{array}{l}y^{\prime}+a y=0 \\
y^{\prime}=a y+b \\
y^{\prime \prime}+w^{2} y=0\end{array}$ \\
\hline
\end{tabular}

\subsection{Ecological Developments}

The analysis of the mathematics programs for the various Tunisian reforms shows a gradual evolution of the habitat from the DE of the habitat "equations" towards the habitat "functions". However, the DE have hardly ever left the niche functional until 1993 which is formed mainly by the functions (exponential, logarithm, trigonometric) the derivative and the complex numbers. The analysis has made it possible to point out a certain stability of the habitat of DE since 2004 in the field of "analysis" but by emphasizing modeling as a skill to be developed in parallel with the construction of this object of knowledge. We summarize these main changes in the following table:

Table 3. Developments in DE niches and habitats over the course of the Tunisian reforms.

\begin{tabular}{ll}
\hline Classic period & -Habitat "Algebra" \\
& -Niche "trigonometry, equation" \\
Period Maths moderns & Habitat "Integration" (the intersection of study are as analysis and algebra) \\
& -Niche "functions" \\
Period Counter-reform & -Habitat "Analyze" \\
& -Niche "functions" \\
Contemporary period & -Habitat "Algebra" \\
& -Niche "Function" \\
Period Current & -Habitat "analyze" \\
& -Niche "functions" \\
\hline
\end{tabular}

\subsection{Praxeological Evolution}

Our analysis has two parts, a quantitative part which takes place in the analysis of the types of tasks most called upon and the expected techniques and a qualitative part related to the analysis of mathematical organization and didactic organization developed around DE. We begin by presenting the types of tasks most often mentioned in the textbooks of the different periods with the exception of the first one, which corresponds to the French textbook at the time.

Table 4. The most requested types of tasks.

\footnotetext{
$\mathrm{T}_{1}$ : Find the family of solutions of a linear differential equation of the first order

$\mathrm{T}_{2}$ : Find a solution to a first order linear differential equation

$\mathrm{T}_{3}$ : Find the family of solutions of a second order linear differential equation

$\mathrm{T}_{4}$ : Find a solution to a second order linear differential equation

$\mathrm{T}_{5}$ : Find the differential equation verified by a given function

$\mathrm{T}_{6}$ : Check if a function is the solution of a given differential equation

$\mathrm{T}_{7}$ : Solve a geometric problem described by a differential equation

$\mathrm{T}_{8}$ : Solve an extra-mathematical problem described by a differential equation

$\mathrm{T}_{9}$ : Draw the solution curve of a differential equation

$\mathrm{T}_{10}$ : Solve a non linear differential equation

$\mathrm{T}_{11}$ : Solve a differential equation of degree $>2$
} 
Furthermore, the conduct analysis of all the activities of the textbook has encountered a progressive loss of formalism attached to the notion of DE typical of the reform of modern mathematics and of the counter-reform. This reduction in ostensives goes hand in hand with an evolution of the status of this notion which seems to further strengthen the tool aspect for modeling mathematical and extra-mathematical problems. This approach is envisaged in a work of simultaneous equations with the construction of new objects of knowledge and the technique of algebraic resolution. These characteristics [26-29] are summarized in the following table.

Table 5. Evolution of the characteristics of the concept of DE according to the analysis criteria selected.

\begin{tabular}{|c|c|c|c|c|}
\hline & Formalism & Types of tasks & Status of the Concept & Semiotic registers \\
\hline Manual 1965 & Strong Moderately & $\mathrm{T}_{1}, \mathrm{~T}_{2}, \mathrm{~T}_{4}, \mathrm{~T}_{6}, \mathrm{~T}_{7}$ & Objet & Absent \\
\hline Manual 1979 & Strong & $\mathrm{T}_{1}, \mathrm{~T}_{2}, \mathrm{~T}_{3}, \mathrm{~T}_{4}$ & Objet & Absent \\
\hline Manual 1993 & Strong & $\mathrm{T}_{1}, \mathrm{~T}_{2}, \mathrm{~T}_{3}, \mathrm{~T}_{4}, \mathrm{~T}_{5}, \mathrm{~T}_{6}, \mathrm{~T}_{8}, \mathrm{~T}_{11}$ & Objet & Almost absent \\
\hline Current manual & Low & $\mathrm{T}_{1}, \mathrm{~T}_{2}, \mathrm{~T}_{3}, \mathrm{~T}_{4}, \mathrm{~T}_{5}, \mathrm{~T}_{6}, \mathrm{~T}_{8}, \mathrm{~T}_{10}, \mathrm{~T}_{11}$ & Tool & ubiquitous \\
\hline
\end{tabular}

\subsection{Strengthening the Dialectics Between Semiotic Registers in an Extra-mathematical Context}

The analysis of the activities proposed in the official manual suggests new dialectics between the registers of semiotic representation (natural, symbolic and graphic language) used in the resolution of the first and second order linear DE in a context which calls upon various fields of experience as illustrated in the following activity taken from the manual:

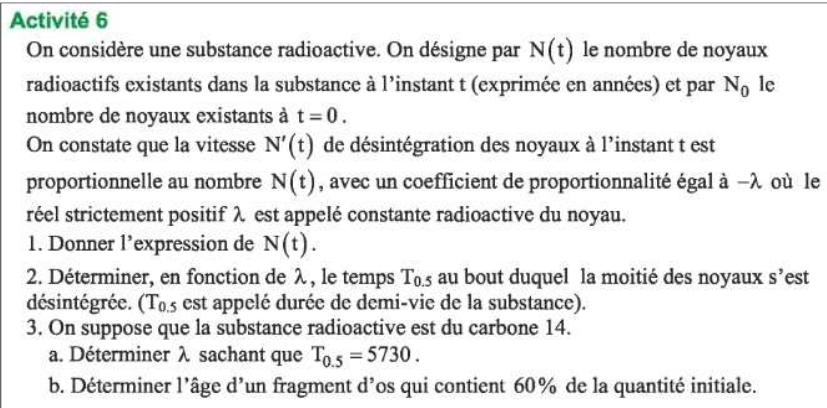

Figure 3. Extract from official terminal manual (2021, p 192).

This is similar to what we could observe in our previous work on algebraic equations and systems of equations and which appears to be a characteristic of the praxeologies developed in the secondary cycle for the current reform.

"This flexibility between the registers which widens the context of application of the objects of knowledge appears to be part of the challenge of the reform of Tunisian education, which remains partly implicit and therefore leaves the teachers responsible for a part of significant autonomy in moving from one register or mathematical framework to another" [5] (p. 115). As we can see from this graph.

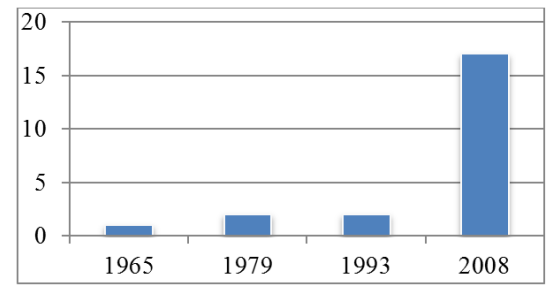

Figure 4. Evolution of semiotic conversion practices.

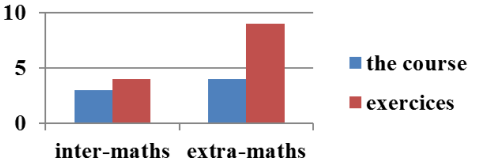

Figure 5. Frequency of intra and extra-mathematical problems in the official textbook.

\subsection{The Focus on Graphic Work}

Several activities of the current official manual focus work in the graphic register by intervening the concept of derivative to approach the concept of $\mathrm{DE}$ as illustrated by the following excerpt.

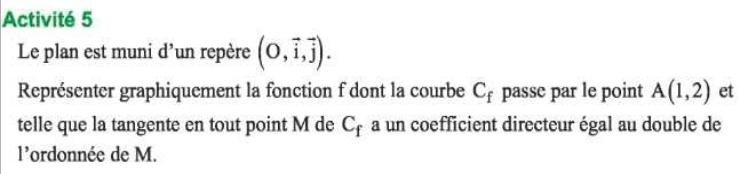

Figure 6. Extract from official terminal manual (2021, p 192).

\begin{tabular}{|c|}
\hline I. Définition \\
\hline Activité 1 \\
\hline 1. Soit la fonction $f: x \mapsto e^{-x}$. Déterminer une relation entre $f^{\prime} e t f$. \\
\hline $\begin{array}{l}\text { 2. Reprendre la même question pour les fonctions } \mathrm{g}: \mathrm{x} \mapsto-2 \mathrm{e}^{-\mathrm{x}} \text { et } \mathrm{h}: \mathrm{x} \mapsto 0,5 \mathrm{e}^{-\mathrm{x}} \text {. } \\
\text { 3. Représenter les fonctions } \mathrm{f} \text {, } \mathrm{g} \text { et } \mathrm{h} \text { dans un méme repère. } \\
\text { 4. Donner d'autres fonctions qui vérifient la relation trouvée dans la première question. }\end{array}$ \\
\hline $\begin{array}{l}\text { Activité } 2 \\
\text { Une expérience consiste à étudier l'évolution d'une population de bactéries. } \\
\text { On désigne par } \mathrm{N}_{0} \text { le nombre de bactéries à l'instant } \mathrm{t}=0, \mathrm{~N}(\mathrm{t}) \text { le nombre de bactéries à }\end{array}$ \\
\hline l'instant $t$ et on note $\mathrm{N}^{\prime}(\mathrm{t})$ la vitesse instantanće d'évolution des bactéries à l'instant t. \\
\hline 1. On constate que $\mathrm{N}(\mathrm{t})=9000 \mathrm{e}^{-0,4 t}$. \\
\hline $\begin{array}{l}\text { a. Donner le nombre de bactéries aux instants } \mathrm{t}=0, \mathrm{t}=10 \mathrm{et} \mathrm{t}=20 \text {. } \\
\text { b. Donner une relation entre } \mathrm{N}^{\prime} \text { et } \mathrm{N} \text {. } \\
\text { c. Déterminer la vitesse instantanće d'évolution aux instants } \mathrm{t}=10 \text { et } \mathrm{t}=20 \text {. } \\
\text { d. Représenter la fonction } \mathrm{t} \mapsto \mathrm{N}(\mathrm{t}) \text {. }\end{array}$ \\
\hline 2. Reprendre les questions précédentes si on suppose que $N(t)=3000 e^{0,4 t}$. \\
\hline
\end{tabular}

Figure 7. Extract from official terminal manual (2021, p 190).

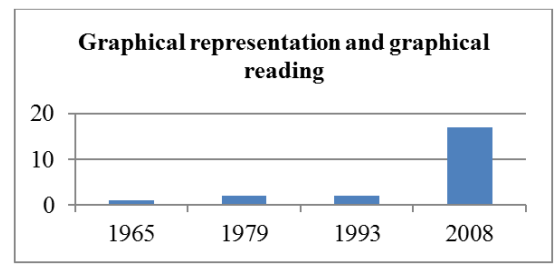

Figure 8. The evolution of the graphs in the chapter DE over the course of the reforms. 


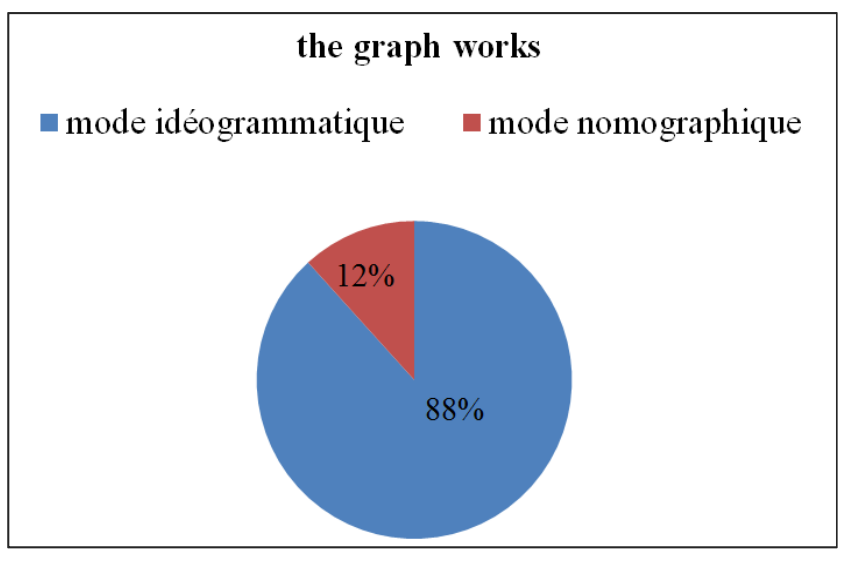

Figure 9. The graph works.

However, the graphic work called upon by the organizations developed around DE seems to be envisaged in the sense of visualizing a unique solution of a problem with initial value, with the objective of reinforcing the achievements of the students around the functions, exponentials and logarithms. The work in the graphic register doesn't seem to be exploited in the interpretation of physical or biological phenomena even if the pseudo-concrete dressing of the situations posed suggests it. In this sense, the operation of the graph appears more in an ideogrammatic mode, as we can see from these two introductory activities to the notion of DE taken from the official manual.

\subsection{A Rapprochement with Reference Knowledge}

What seems interesting to us at the level of the mathematical organizations developed by the manual around this notion is the existence of situations that refer to what we have encountered in scholarly knowledge. In particular, situations which articulate graphic properties of solution curves (implicitly fields of vectors) with work on algebraic expressions, as we can see in this extract:

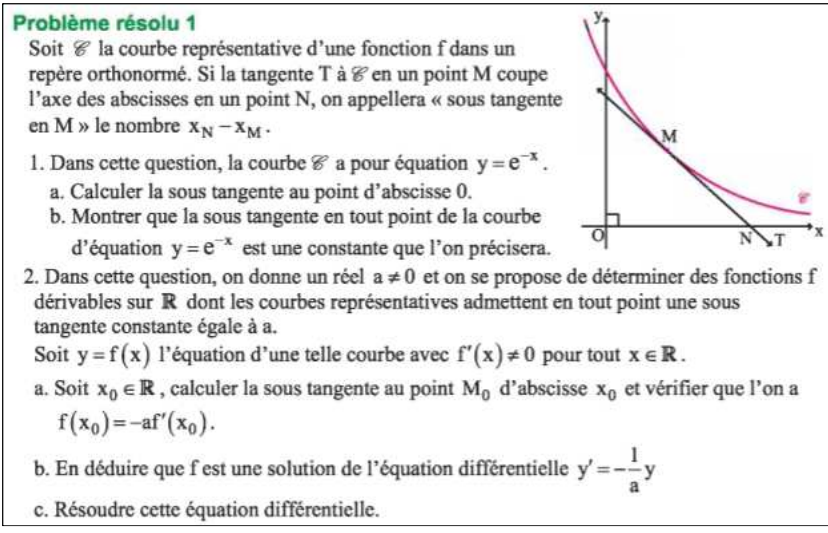

Figure 10. Extract from official terminal manual (2021, p 197).

In the first question, this is determining a property of the sub tangent at a point associated with the graphical representation of the exponential function. In the second question on proposing to translate in the symbolic register linked to the linear DE of the first order of the results obtained from the graph. Indeed the graphical representation of the function $\mathrm{f}$ admits a sub tangent equal to a non-zero constant a if and only if $\mathrm{f}$ and solution of the DE: $y^{\prime}=-\frac{1}{a} y$. This dynamic perception of the objects of knowledge by means of the graph (the tangent in M) makes it possible to discover from the numerical invariant of the family of curves "the sub-tangent solution of a DE of the form: $y^{\prime}=a y$ is equal to a constant". This articulation between the two registers makes it possible among other things to account for the different properties of the graphic representations of solutions. The epistemological issues underlying this activity seem to play an interesting role in the mathematical organization developed by the authors of the textbooks around graphic work. This work seems to initiate the properties of the fields of vectors linked to the DE encountered in history with the problem of Debeaune (16011652). This involves constructing curves in a geometrical context from the properties of the tangent: "Find a curve $y(x)$ for which at each point $\mathrm{P}$, the segment delimited by the intersection points with the objective of $\mathrm{x}$ of the tangent (PT) and the perpendicular (PN) to this same $x$ is constant"

\subsection{Results Relating to the Institutional Analysis}

The analysis carried out within the framework of this work put forward a clear evolution of the mathematical and didactic organizations developed around the DE. For the reform of modern mathematics, the approach to teaching DE seems essentially "equational", the types of DE presented are very limited and their treatment is always summoned in the algebraic register. The programs of the counter-reform suggest an introduction to the analysis which gradually detaches itself from the field of algebra. The DE thus changes habitat and appears as the crowning of the notions of analysis. The "structural" context specific to the reform of modern mathematics in connection with set notions and the concept of function appears in the environment of DE. These are introduced according to their "object" dimension and are considered from a structural aspect. The resolutions essentially call for algorithmic techniques and an absence of articulation between the semiotic registers. In addition, to these two reforms, the teaching of this notion is limited to particular fields and does not constitute an object of teaching for scientific sections. In the curricula of the 1990s, and because of their use in the physical sciences, DE reappeared in the final math-science and math-technical programs. New types of $\mathrm{DE}$ of the form $a y^{\prime \prime}+b y^{\prime}+c y=0$ reappear in textbooks, in the same habitat as the previous ones, but the algebraic aspect of the treatment of these equations remains dominant. With the advent of the reform in 2004, a new perspective for teaching mathematics appears explicitly in official textbooks, giving more room to the modeling of extra-mathematical situations. DE now plays a transversal role favoring an interdisciplinary approach and the development of activities. Calling on a variety of contexts and fields of experience. They are now a teaching object for the mathematics and experimental sciences sections and reinforce the teaching of usual functions, logarithm, 
exponential and trigonometric as well as the consolidation of knowledge on the primitives of functions. A specificity of the praxeologies developed around this object of knowledge also appears in the dialectics convened between the semiotic registers. In addition, the graphic register now occupies an important place in current programs and the technological discourse that accompanies the technique of graphic representation becomes explicitly justified by an explicit technological-theoretical block in connection with exponential functions. However, this work is generally limited to solution illustration tasks or to a graphic reading of the properties of tangents (slope, sub-tangent, coordinates, and directing vector.) which aims more at consolidating knowledge in analytical geometry. This does not prevent thinking of a progressive force from a qualitative resolution of DE.

Furthermore, current institutional practices seem to be evolving into a more "dynamic" teaching approach that involves a simultaneous study of knowledge objects at the same time as the activity of functional modeling in an interdisciplinary perspective. This aspect is nourished by the sets of frames and the flexibility between the registers in contrast to the periods of past teaching which refer to a more "static" approach to the field of analysis.

This leads us to question the visibility of the changes identified and their price taken into account by the teachers.

1) Do teachers perceive this dialectic between the different algebraic, functional and graphic registers.

That emerges throughout the activities of the textbook?

2) Do they take into account the graphic work called several times?

3) Do they give the expected importance to the work of modeling extra-mathematical situations?

4) In the absence of any technological and theoretical discourse on this subject, are teachers equipped to undertake these innovations in their practices?

5) Do they live and how?

\section{Analysis of Learned Knowledge by Teachers}

Our survey of teaching practices in this context of Tunisian educational reform is undertaken by a study of extracts from student notebooks more than to "what to know". We consider them as a first revealing of teaching practices in terms of resistance or change. In our opinion, it allows us to identify the main characteristics of the institutional practices studied for teachers, more or less exploited.

We used these notebooks as revealers of the practices of experienced teachers (having between 15 and 20 years of profession.) These teachers practiced in different regions of Tunisia in scientific fields: Mathematics (M) or Experimental Sciences (S). Some teachers have agreed to give us some course materials as well as "model" student notebooks. According to them, these notebooks are more detailed than their lesson sheets which are limited, in general, to the objectives or to references to the activities chosen in the official manual.

All the notebooks collected are determined both as a "course" part but also all the activities and all the exercises that have been the subject of a correction by the teachers. The data disseminated is illustrated in the following table:

Table 6. Data collection.

\begin{tabular}{|c|c|c|c|c|}
\hline Regions & Establishment (Secondary School) & Number of notebooks & Section & School year \\
\hline \multirow{4}{*}{ Néfza } & Ammar Farhat & 2 & $4_{\mathrm{S}}$ & $2017 / 2018$ \\
\hline & Néfza & 1 & $4_{\mathrm{s}}$ & $2017 / 2018$ \\
\hline & \multirow{2}{*}{ Taher Ben Achour } & 1 & $4_{\mathrm{S}}$ & $2017 / 2018$ \\
\hline & & & $4_{M}$ & $2017 / 2018$ \\
\hline Béja & Ibn Al-Heithem & 1 & $4_{M}$ & $2017 / 2018$ \\
\hline Kef & Pilote Kef & 1 & $4_{M}$ & $2017 / 2018$ \\
\hline Ghardimou & Gadrimou & 2 & $4_{S}$ & $2017 / 2017$ \\
\hline \multirow{2}{*}{ Tabarka } & 2Mars & 1 & $4_{M}$ & $2017 / 2018$ \\
\hline & Ain Mazouz & 1 & $4_{M}$ & $2017 / 2018$ \\
\hline
\end{tabular}

We initially carried out a macro analysis aiming to identify the most striking characteristics of the praxeologies developed by these teachers identified in the student notebooks by referring to the analysis criteria mentioned above. We seek more particularly to identify the most striking aspects of the knowledge prepared around the first order and second order DE with regard to institutional praxeologies.

1) What is the didactic preparation of the knowledge to be taught around this notion?

2) How do they introduce it?

3) What importance do they place on solving techniques?

4) What is the place of modeling in prepared knowledge?
5) How does the graph work at the level of developed mathematical organizations?

\subsection{A Relationship to Knowledge Developed Around the Object Dimension}

In most of the notebooks selected for the study (87\%), the DE are introduced by means of a definition which presents the object of knowledge in a naturalized manner as an algebraic equation of which the unknown is a function. This is the resolution that appears to be a teaching issue for teachers. Some limit themselves to immediately presenting the vocabulary associated with differential equations 
followed by theorems relating to the resolution, as we can see in this extract.

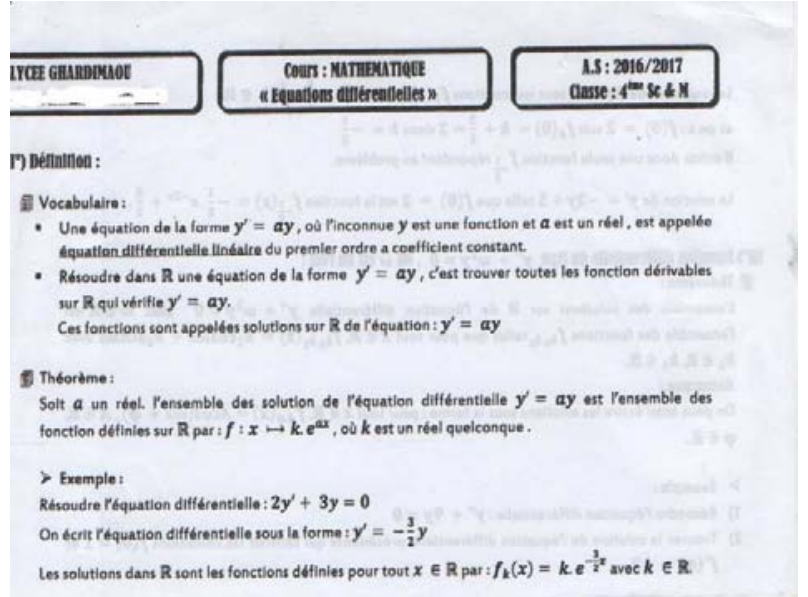

Figure 11. Extracts: Notebook 1.

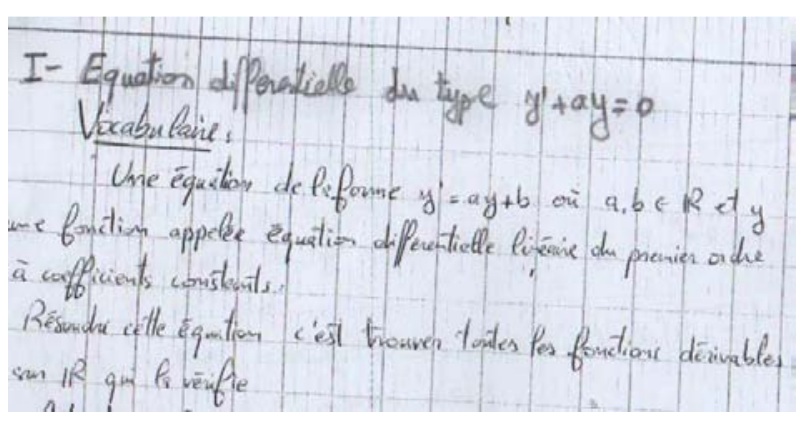

Figure 12. Extracts: Notebook 2

The didactic organization developed in these notebooks seems out of step with that presented by the institution. The moment of the first encounter with this object of knowledge, considered in an approach of modeling mathematical and extra-mathematical situations, does not appear in the knowledge prepared by a majority of teachers. The "object" dimension predominates in the praxeologies developed in these notebooks.

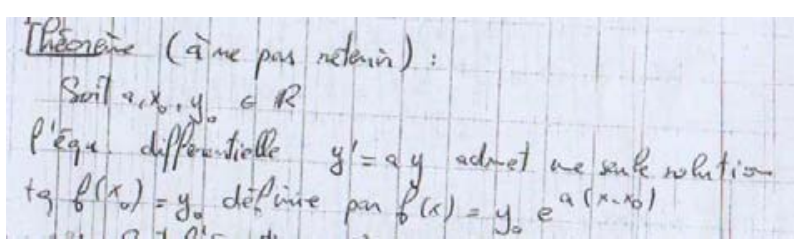

Figure 13. Extracts: Notebook 3.

\subsection{The Lack of Technological Background Around Algebraic Resolution}

In more than $60 \%$ of the analysed notebooks, we note the absence of a technological-theoretical discourse developed around the algebraic technique of solving, but this one is summoned by most of the local mathematical organizations in the manual. In particular, most of the mathematical organizations prepared by the teachers do not develop justifications around the existence of solutions or their uniqueness under certain conditions. And, some teachers even go so far as to state the uniqueness of solutions theorems without making a teaching issue. We see in this notebook the mention "do not retain"

Yet in the guidelines of the official programs on can read: "We will prove the existence and the uniqueness of the solution of a DE of the type $y^{\prime}=a y+b$, a and $b \in \mathrm{IR}$, with initial condition We will prove the existence and the uniqueness of the solution $d$ 'a linear DE of the type $y^{\prime \prime}+$ $a^{2} y=0, a \in R$ with initial conditions."'[34] (p. 73).

The development of reasoning in this direction does not seem to constitute a teaching issue for this study theme. The mathematical organizations to be seen through these notebooks present techniques essentially contextualises by means of simple examples which consist in an immediate application of the formulas $\left(f(x)=k e^{a x}, \mathrm{k}\right.$ real $)$. We find this same organization for first order equations with constant second members.

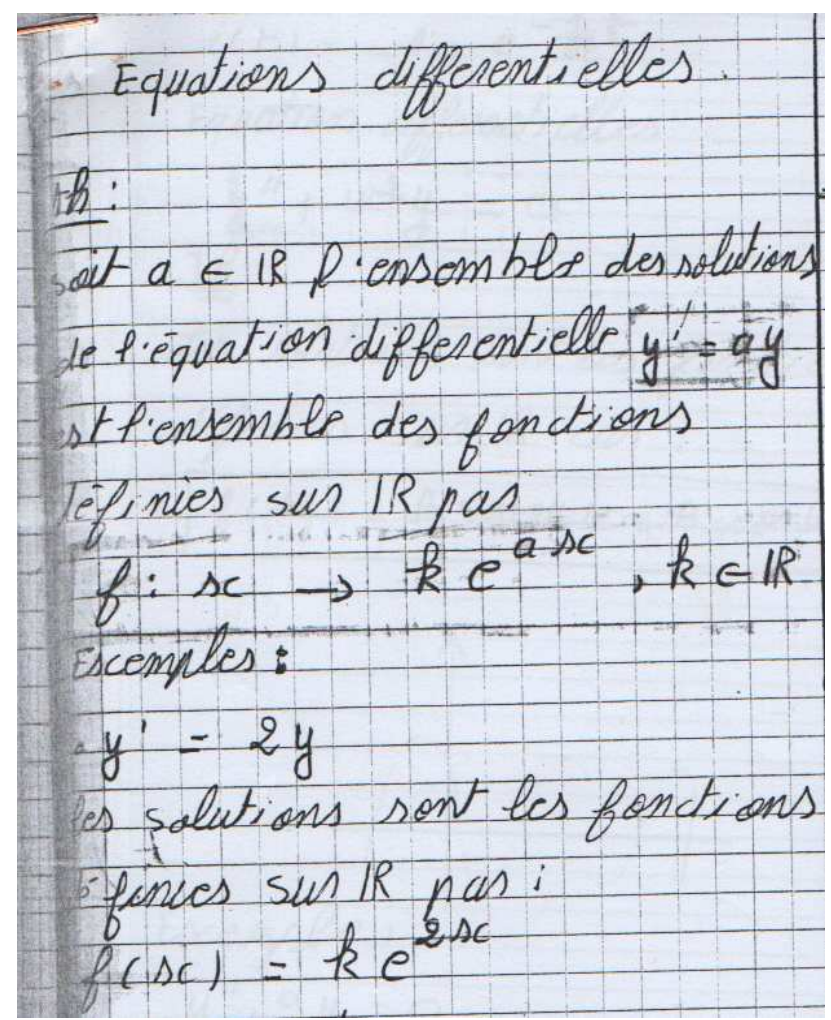

Figure 14. Extracts: Notebook 4.

Among the five notebooks which offer a justification around the resolution of this type of equations, four are content to accompany this technique with a necessary and not a sufficient condition to prove the existence of the solutions. In these mathematical organizations, we do not try to find these solutions by a resolution algorithm that can be perfectly mastered by the students but rather to justify that if such solutions already exist, they are implemented in the given form. Only one meaning is retained in the demonstration of the manual, the other meaning is excluded from the praxeology developed in these notebooks. 


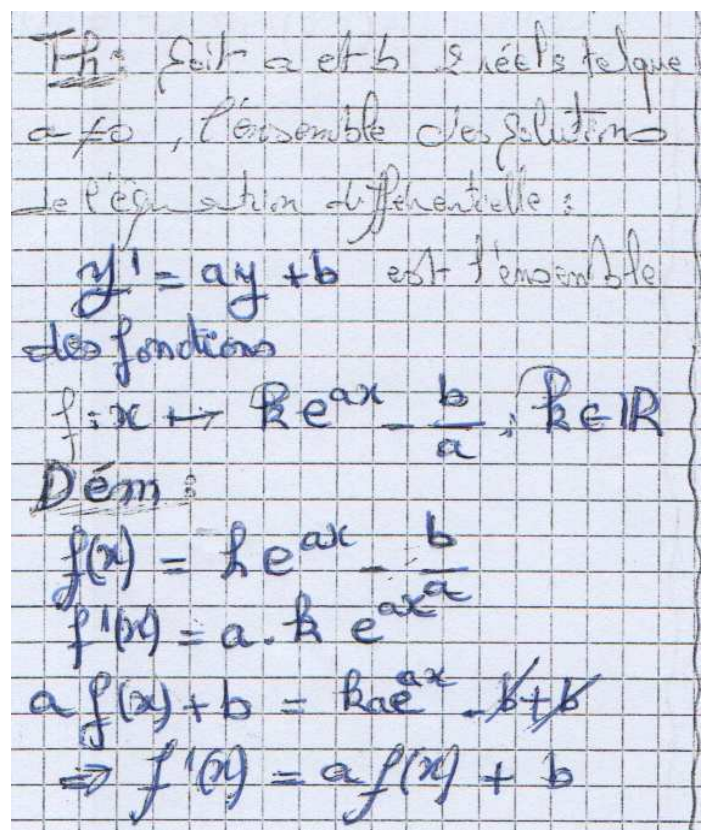

Figure 15. Extracts: Notebook 5.

On the other hand, the mathematical organizations developed in notebook 6 around the resolution of DE of the form $y^{\prime}=a y$ constitute an exception which seems to conform to the reference praxeologies around the technique of resolution. We see the algorithm for solving the homogeneous equation appears explicitly.

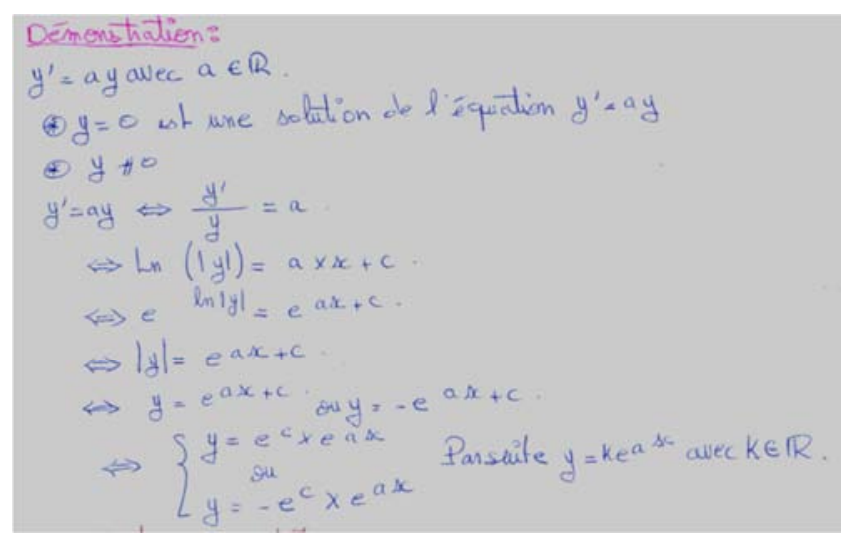

Figure 16. Extracts: Notebook 6.

\subsection{Graphic Work Is Not a Teaching Issue}

The analysis carried out on all the notebooks reveal the little interest given to graphic work (8/10 notebooks) which is explicitly put forward in the praxeologies to be taught around DE, even if the functioning of the graphic in these organizations mathematics seem to be at the service of an investment of knowledge around the study of usual functions, as a solution of a first order DE with initial value, as we can see through this extract:

The functioning of the graphic in the proposed activities can partly explain the resistance of teachers to mobilize the graphic register and strengthen the links between the objects of knowledge of the analysis but does not explain the choice of a focused practice to the detriment of a development of links between the algebraic and graphical registers clearly suggest by the official manual.

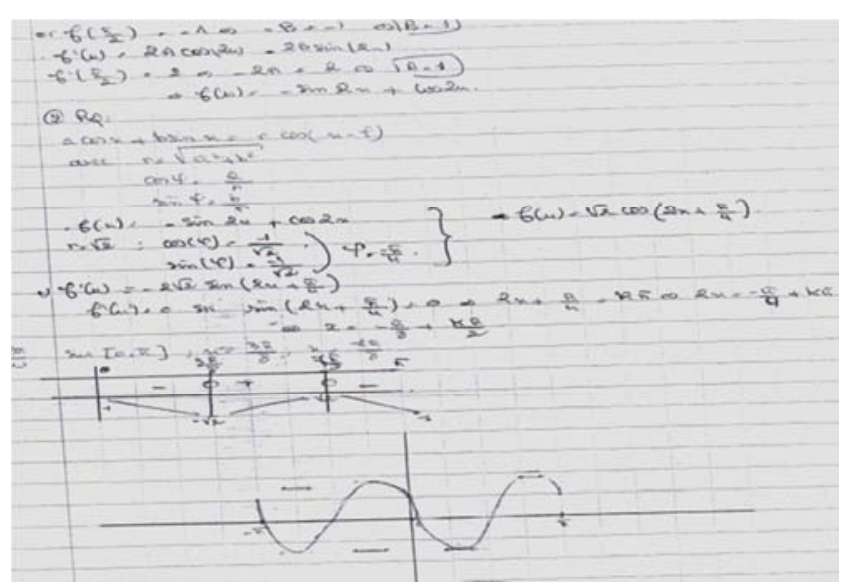

Figure 17. Extracts: Notebook 7

\subsection{Modeling: A Devalued Practice}

Most of the mathematical organizations developed in the notebooks selected for the study (7/10) do not prepare activities for modeling and solving extra-mathematical problems. Most of the proposed tasks involve solving DE in a purely mathematical context. Only 3 notebooks seem to stand out by showing situations within the framework of physical quantities which are modeled by linear DE of the first order with an initial condition. However, the activity's answer does not reveal the task of graphing or reading graphs in relation to the interpretation of the observed phenomenon. The didactic preparation of these activities seems to focus more on a (differential) equation in a procedural conception, without worrying about giving meaning to the objects of knowledge to be taught. The following excerpt illustrates the resolution algorithm without going any further:

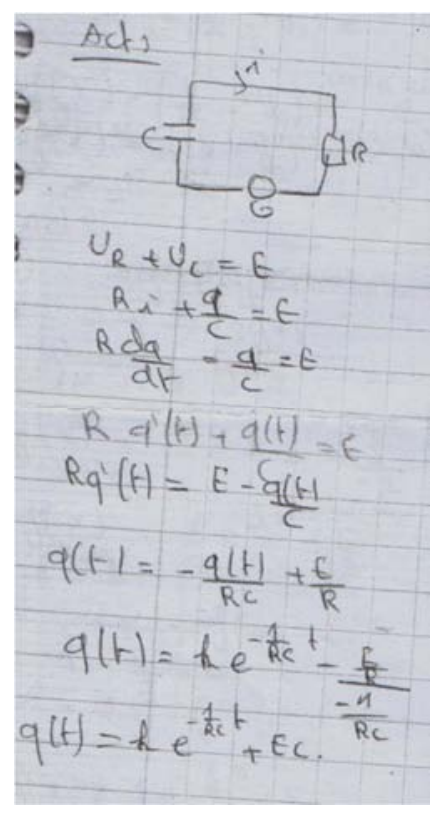

Figure 18. Extracts: Notebooks 8-10. 
This finding confirms those of [24] who have previously encountered epistemological obstacles encountered by students following their university course in the conceptualization of $\mathrm{DE}$ at the interface of physics and mathematics.

"Students have notable difficulties considering the DE object with model status concerning two complementary aspects: lexicon and semantics. Indeed, such a model must be expressed using mathematical symbols and it must display the proposed physical system ... Note also that a large part of the students have difficulty in correctly grasping what a DE represents when it describes a physical situation" [24] (p. 184).

The interdisciplinary approach put forward by the Tunisian reform does not seem to be adopted by most mathematics teachers who confine themselves to a technician centered essentially on algebraic resolution techniques to the detriment of the "structuralist" appearance in relation to the technological foundations yet summoned in the official manual. It seems that the practice of modeling as contextualized problem-solving resists the change to this approach which is more aimed at developing both semiotic and cognitive skills.

\section{Conclusion}

In conclusion, this research allows us to approach the teaching of Differentials equations from the point of view of exogenous disturbances of the institutional system and endogenous disturbances specific to teaching practices. Three dimensions of analysis were taken into account in this study: historical-epistemological dimension which makes it possible to identify the dynamic nature of the notion of DE through the stages of its constitution and to determine its meaning through the problems addressed in teaching and their development, an institutional dimension addressed through official programs and textbooks, making it possible to question the conditions and constraints that weigh on teaching practices and a professional dimension which revolves around the didactic preparation of the knowledge to be taught around DE via an analysis of student notebooks. It points to the difficulty for teachers to implement, among other things, the institutional and innovative characteristics of the approach to this notion. Prepared practices shifted from the institutional practices developed in the current reform. How could we explain the robustness of the practices observed, verify more than in the previous research that we have included in the same context $[5,6]$, for another subject of study and a different level of teaching, a phenomenon of similar resistance has been put forward. How can the robustness of practices be explained after a fairly significant adaptation phase to the reform? While our work has shed light on certain phenomena linked to teaching practices, today it seems to us to pose a new problematic of the dissemination of a reform, or of a new global teaching project (field of study, even a discipline). There is an essential reality here: teachers can apply a reform in a "superficial" way, the induced change has only a real impact if it is meaningful for teachers, that they understand the goals, adhere to its orientations and appropriate its foundations through adaptations that are part of a learning process. This problem seems to refer to questions related to the training of practices if we consider initial and continuing training as an instrument allowing an adaptation or even a transformation of practices.

\section{References}

[1] Artaud, M. (1997). Introduction à l'approche écologique du didactique. L'écologie des organisations mathématiques et didactiques, In Bailleul et al. (eds.), Actes de la IXème Ecole d'Eté de Didactique des Mathématiques 1997, pp. 101-139. Houlgate.

[2] Artigue, M. (1989a). Une recherche d'ingénierie didactique sur l'enseignement des équations différentielles du premier cycle universitaire, Cahier du séminaire de Didactique des Maths et de l'Informatique de Grenoble, IMAG, pp. 183-209.

[3] Artigue, M. (1989b). Ingénierie didactique, Recherches en Didactique des Mathématiques, vol. 9, n³, pp. 281-308. La pensée Sauvage. Grenoble.

[4] Assude, T. (2004). Etude du curriculum de mathématiques entre changements et résistances, Liens entre écologie et économie didactique. Actes du séminaire national de didactique des mathématiques. ARDM et IREM pp 317-334, Paris 7.

[5] Ben Nejma S. (2009). D'une réforme à ses effets sur les pratiques enseignantes: une étude de cas en algèbre dans le contexte scolaire tunisien. Thèse des universités de Paris 7 et de Tunis.

[6] Ben Nejma, S. (2010). Quel impact d'une évolution du curriculum officiel sur les pratiques enseignantes ? Etude de cas dans le contexte tunisien. Petit $x, 82,5-30$.

[7] Ben Nejma, S. (2012). Pratiques enseignantes et changements curriculaires: une étude de cas en algèbre élémentaire. Dans J.-L. Dorier et S. Coutat (dir.), Enseignement des mathématiques et contrat social: enjeux et défis pour le 21e siècle. Actes du colloque EMF 2012 (p. 1133-1142). Université de Genève, Genève.

[8] Ben Nejma, S. (2020). Exploitation de l'histoire dans une analyse didactique du développement de la pensée fonctionnelle au début de l'enseignement secondaire tunisien. Revue Québécoise de didactique des mathématiques. Vol 1. pp 38-69.

[9] Bloch, I. (2000). L'enseignement de l'analyse à la charnière lycée / université: connaissances, savoirs, et conditions relatives à la validation. Thèse, Université Bordeaux 1 .

[10] Chau O. et Pluvinage F (1999). Comparaison de compétences dans les approches algébriques, qualitative et informatique des équations différentielles ordinaires en première année universitaire. Recherche en didactique des mathématiques. Vol. $19, \mathrm{n}^{\circ} 2$, p. $195-220$.

[11] Chevallard, Y. (1998). Analyse des pratiques enseignantes et didactique des mathématiques: L'approche anthropologique. Actes de l'U. E. de la Rochelle. 
[12] Chevallard, Y. (1991). La transposition didactique. Du savoir savant au savoir enseigné. Grenoble. La pensée sauvage.

[13] Chevallard, Y. (1997). Familière et problématique, la figure du professeur, Recherches en Didactique des Mathématiques 17 (3), 17-54.

[14] Chevallard, Y. (1999). Analyse des pratiques enseignantes en théorie anthropologique du didactique, Revue de didactique des mathématiques, 19 (2), 221-266. Grenoble. La pensée Sauvage.

[15] Chevallard, Y. (2002). Organiser l'étude 1. Structures et Fonctions. In J-L. Dorier\& al. (eds) Actes de la 11ième Ecole d'été de didactique des mathématiques -Corps- 21-30 Août 2001. Recherches en Didactique des Mathématiques.

[16] Chaachoua, A. (1997). Fonctions du dessin dans l'enseignement de la géométrie dans l'espace. Etude d'un cas: la vie des problèmes de construction et rapports des enseignants à ces problèmes, Thèse de doctorat, Université Joseph Fourier- Grenoble.

[17] Coulange, L., Ben Nejma, S., Constantin, C. et Lenfant, (2012). Des pratiques enseignantes aux apprentissages des élèves en algèbre. Dans L, Coulange et-P Drouhard. JL, Dorieret A, Robert (dir), Enseignement de l'algèbre, Bilan et perspectives, Recherches en didactique des mathématiques- $H$ $S$ (pp. 57-79). Grenoble: La Pensée Sauvage.

[18] Douday, R. (1986). Jeux de cadres et dialectique outil-objet, Recherches en Didactique des Mathématiques, vol. 7, n². La pensée Sauvage, Grenoble.

[19] Duval, R. (1993). Registres de représentation sémiotique et fonctionnement cognitif de la pensée, Annales de Didactique et de Sciences Cognitive, n5, pp. 37-65. IREM de Strasbourg.

[20] Jabrane, A (2019). Une élude didactique de l'évolution de l'enseignement des équations différentielles en terminale scientifique et son impact sur les pratiques enseignantes dans le contexte tunisien. Mémoire de master de recherche en didactique des mathématiques-ISEFC-UVT.

[21] Lacasta, E. (1995). Les graphiques cartésiens de fonctions dans l'enseignement secondaire des mathématiques: illusions et contrôles, thèse de doctorat. Université de Bordeaux 1.

[22] Ravel, L. (2003). Les programmes à la classe: Etude de la transposition didactique interne, thèse de doctorat. Université Joseph Fourrier, Grenoble.
[23] Rajonson, L. (1988). L'analyser écologique des conditions et des contraintes dans l'étude des phénomènes de transposition didactique: trois études de cas. Thèse de troisième cycle, Université d'Aix-Marseille II.

[24] Saglam, A. (2004). Les équations différentielles en mathématiques et en physique: étude des conditions de leur enseignement et caractérisation des rapports personnels des étudiants de première année d'université à cet objet de savoir, Thèse de doctorat, Université Joseph Fourier, Grenoble I.

[25] Wanner, G. (1988) Les Équations différentielles ont 350 ans. L'enseignement Mathématique, 34, 365-385.

[26] Tunisian Manual. (1965), Algebra, sixth year of Secondary Education, Section: Mathematics, Volume 2, Republic of Tunisia, State Secretariat for National Education, pedagogical office Edition STD.

[27] Tunisian Manuel. (1979), Mathematics, 6th year of Secondary Education, Section: Industrial Technique, Volume 1, Republic of Tunisia, Ministry of National Education, CNP (Experimental Edition 1979).

[28] Tunisian Manuel. (1993), Mathematics, 7th year of Secondary Education, Section: Math-Sciences, Math-Technique, Republic of Tunisia, Ministry of Education and Science CNP, code 222734 .

[29] Manuel Tunisien. (2002), Mathématiques, 7ème année de l'Enseignement Secondaire, Section: Mathématiques, Tome 1, République Tunisienne, ministère de l'éducation CNP, code 222445 .

[30] Official secondary education programs. (1959), Mathematics, Republic of Tunisia, Ministry of National Education.

[31] Official secondary education curricula (1968). Mathematics, Republic of Tunisia, State Secretariat for National Education.

[32] Official secondary education programs. (1970), Mathematics, Republic of Tunisia, Ministry of Education, Youth and Sports, (Applicable from September 16, 1970).

[33] Official secondary education programs. (1982), Mathematics, Republic of Tunisia, Ministry of National Education. National Pedagogical Center (CNP).

[34] Official secondary education programs. (2004), Mathematics, Republic of Tunisia, Ministry of National Education. General Directorate of Programs and Continuing Education. https://sigmaths.net/Reader.php?var=manuels/4M_t1.pdf 